\title{
Mise-en-scène e experiência estética: o trabalho do espectador em A falta que me faz
}

César Geraldo Guimarães, Cristiane da Silveira Lima e Victor Ribeiro Guimarães

\section{Resumo}

Ao se deter na escritura fílmica de $A$ falta que me faz, o texto procura descrever como se dá 0 aprendizado prático (dos sentidos e do sentido) que a sessão de cinema oferece ao espectador. Para isso buscamos identificar a vinculação entre a mise-en-scène documentária e o engajamento (psíquico, sensorial, afetivo, imaginário) que ela solicita do espectador. Trata-se, portanto, de alcançar este caminho do meio entre a cena do filme e a experiência do espectador, de modo a apreender a maneira com que ele vem - por meio da identificação e também do estranhamento - a cortar transversalmente a relação inicial que se estabelece entre quem filma e os sujeitos filmados.

\section{Palavras-Chave}

Documentário. Experiência estética.

Mise-en-scène. Espectador.

César Geraldo Guimarães I cesargg6@gmail.com Doutor em Literatura Comparada pela Universidade Federal de Minas Gerais (UFMG). Professor do Programa de Pós-Graduação em Comunicação Social da Universidade Federal de Minas Gerais (PPGCOM/UFMG).

Cristiane da Silveira Lima | crislima1@gmail.com Mestre em Comunicação Social pela Universidade Federal de Minas Gerais (UFMG).

Doutoranda do Programa de Pós-Graduação em Comunicação Social da Universidade Federal de Minas Gerais (PPGCOM/UFMG).

Victor Ribeiro Guimarães I guimaraesvictor@ufmg.br Mestre em Comunicação Social pela Universidade Federal de Minas Gerais (UFMG).

\section{Heterogeneidade de \\ recursos e exigências da escritura}

Desde a abertura, A falta que me faz (2010), de Marília Rocha, convoca o espectador para um minucioso trabalho com o olhar e a escuta. 0 filme se inicia com uma sucessão de doze imagens fixas, acompanhadas por uma voz feminina que, à capella, canta Cena de um filme, de Eduardo Costa. A primeira imagem traz um pequeno vaso de antúrio, em primeiro plano, à esquerda do quadro, e, acima dele, um nome gravado na madeira. Ao fundo, levemente desfocadas, as casinhas de um povoado. A canção sertanejoromântica, ao falar da perda do amor genuíno e único, dialoga com as imagens dos corpos femininos, dos quais se recorta o colo, o pescoço, partes do rosto, pernas, mãos que afastam delicadamente a blusa para exibir o nome do amado, inscrito no peito (rústica escarificação amorosa). Os corpos exibem diferentes adereços: colares, anéis, brincos, pingentes em forma de coração. Costumeiramente tomados como fetiches (pelo olhar masculino), tais adornos adquirem 0 valor de amuletos que, como bem notou Cláudia 
Mesquita (2010), figuram, de uma só vez, tanto a ausência do objeto de desejo quanto a espera ou 0 vazio que 0 amparam, em um filme que, ao por em cena - e em causa - o desejo feminino, o faz deslocando os homens para o extracampo.

Se Eros adentra a mise-en-scène dos corpos filmados - cuja presença é sentida na duração dos planos, oferecida ao olhar -, tal deslocamento traz implicações decisivas: assim como a voz feminina (com seu timbre) inverte 0 ponto de vista masculino da canção sertaneja, as aparições do grupo das meninas, por força da relação que se estabelece com elas, complicam em muito - felizmente! - 0 voyeurismo que anima todo espectador. Para além da figuração dos corpos, é a relação entre quem filma e quem é filmado que se torna coisa sensível, que se prolonga, que se quer prolongar (até nas pausas e nos silêncios), sustentada, de parte a parte, pelo desejo: delas, antes de tudo, de entrarem e permanecerem no filme; da equipe, que as acolhe, mas também que as procura com delicadeza, que insiste (pergunta, acompanha), mas também recua; desejo nosso também, atraídos por uma força de imantação que nos faz pender para o mundo que elas habitam. No tempo suspenso da sessão, temos a chance de nos retirar de um entorno familiar e indiferente em sua repetição, ele não nos fascina mais - e de nos aproximarmos do mundo do outro, podendo experimentá-lo na matéria pela qual seus índices de alteridade se expressam: voz, rosto, paisagem, música. Essa projeção que nos lança no mundo dos outros só é possível se os traços desse universo surgem organizados por uma escritura que nos faz experimentá-los sob as condições do espaço e do tempo modulados pelo filme.

Após a aparição de trechos manuscritos na parede - de tom confessional, dedicados ao tema da saudade e da permanência do amor - e do rosto feminino oculto pela mão - só vemos os rolos que prendem os cabelos -, surgem as primeiras imagens-movimento, em planos fixos, de diferentes enquadramentos, fustigados pelo vento da Serra do Espinhaço. Um grupo, filmado de muito longe, do alto, sobe a montanha; mulheres colhem sempre-vivas, em um plano de conjunto - ouvimos o murmúrio das vozes e risos; no plano seguinte, uma das moças surge mais próxima, colhendo as flores, até que sai lentamente do quadro; em seguida aparecem três moças - adivinhamos talvez o refrão de uma canção, em meio ao ruído do vento - e o plano seguinte, aberto, mostra a paisagem montanhosa. Súbito, planos muito próximos dos rostos e dos corpos que dançam apresentam, uma a uma, as protagonistas do filme - identificadas pelo nome próprio -, enquanto a música preenche a cena com forte intensidade.

Logo após um corte, já sem a música que preenchia 0 ambiente e transbordava 0 quadro, a câmara segue Alessandra, que se dirige ao balcão, chama por uma amiga - a quem cochicha algo -, e depois se dirige para o fundo do quadro, quase na escuridão. Pelo que a cena apenas sugere, estamos já diante de uma personagem, e no escuro que ela adentra - para onde irá? - pressentimos 
que estamos no limiar de um microcosmo que aos poucos o filme descortina. Finda a abertura, vemos Priscila, sentada na grama; com caneta esferográfica e agulha, ela tatua na uma flor na pele negra e terrosa da perna, cicatriz que sela 0 amor. "Essa marca vai ficar de vera", comenta uma das amigas que presencia 0 gesto.

Em poucos minutos, o espectador se vê diante de uma diversidade de recursos expressivos, articulados de maneira complexa e polissêmica, e que 0 obrigam a dar conta do que escapa à compreensão imediata - 0 trabalho do sentido, sabemos bem, só se completa après coup. Ao exibir materialmente 0 quanto mostrar é esconder, o filme - na contracorrente do espetáculo permite ao espectador lidar com o buraco no interior do seu próprio sistema perceptivo e cognitivo, tal como sublinha Jean-Louis Comolli (2008, p. 192):

\begin{abstract}
Mostrar nada tem de passivo, de inerte, de neutro, e qualquer que seja a clareza do ser ou do momento representados, a ação de mostrar permanece opaca, permanece uma ação, uma passagem, uma operação, isto é, uma turbulência, um distúrbio, uma não-indiferença. Essa opacidade do gesto criador nos incomoda, e preferimos fazer como se o mundo nos fosse dado de pleno direito e de boa vontade, translúcido e leve, desprovido de ambigüidades, livre da servidão do trabalho da linguagem e do jogo da relação, sem montagem e desmontagem.
\end{abstract}

Ao se deter na escritura fílmica de A falta que me faz, este texto busca descrever como se dá 0 aprendizado prático - dos sentidos e do sentido - que a sessão de cinema oferece ao espectador. Para isso procuramos identificar a vinculação entre a mise-en-scène documentária e 0 engajamento - psíquico, sensorial, afetivo, imaginário - que ela solicita àqueles que se colocam diante do filme. Trata-se, portanto, de alcançar este caminho do meio entre a cena do filme e a experiência do espectador, de modo a apreender a maneira com que ele vem - por meio da identificação e também do estranhamento - a cortar transversalmente a relação inicial que se estabelece entre quem filma e os sujeitos filmados. 0 quadro teórico-conceitual que suporta essa indagação em torno da experiência estética proporcionada pelo filme vem inteiramente das formulações do cineasta, crítico e teórico JeanLouis Comolli.

Se fosse possível encontrar uma figura-chave que resume as proposições de Comolli em torno da relação entre 0 filme e 0 espectador - e por que não, em torno da potência estética e política do cinema - esta poderia ser a do entredois: figura maleável, paradoxal, orientada pelo deslocamento incessante de seus pólos, em um contínuo jogo de contrários, sem síntese nem apaziguamento, em que cada elemento, em sua afirmação, convoca a diferença em relação ao outro. É assim que se dispõem, no pensamento do autor, as relações entre a realidade e a representação, a vida e o espetáculo, a crença e a dúvida, o campo e o fora-de-campo, o visível e 0 invisível, todas elas derivadas da operação cinematográfica. Ao mesmo tempo "regulada 
e aberta, organizada e aleatória [...]", essa operação tem como condição a presença de um espectador que age sobre 0 espetáculo pelo seu interior: não apenas por "receber e perceber, membrana sensível, mas vibrar, à sua maneira singular, triagem, filtro, recalque, agindo, por sua vez, como havia feito o quadromáscara da câmera, escolhendo, ocultando, isto é, elaborando a partir de uma elaboração" (COMOLLI, 2008, p. 161-162).

No caso do filme de Marília Rocha, o espectador é convocado a se reapropriar da especificidade da mise-en-scène documentária, feita de uma matéria que lhe resiste e que, simultaneamente, a constitui internamente: as outras mises-en-scène produzidas pelas instituições da vida social. É apenas sob essa condição que o filme pode documentar alguma coisa de real: "um fim de mundo qualquer, realidade de uma relação, singularidade de uma subjetividade" (COMOLLI, 2009, p. 113, tradução nossa). 0 que é próprio do documentário é que ele não é soberano diante daquilo que filma: os fatos, coisas, corpos, pessoas, situações lhe opõem uma resistência. Eles duram, persistem, não são de todo "filmáveis", não se dobram à vontade dos que querem filmá-los, teimam em existir para além da sua entrada em cena. Que essa relação contrariada (mas, ainda assim, relação) fique registrada no filme, faz toda a diferença para o documentário e 0 seu espectador. Ao garantir que nem tudo se torna visível, ela impõe àquele que vê e escuta um limite: é sob esse constrangimento (uma castração) que 0 espectador pode desenvolver sua atividade.
Falamos do trabalho do espectador, mas é possível que também não estejamos longe da graça (alguma coisa chega até nós como um acontecimento, uma descoberta, um desnorteamento). Por uma via ou por outra, ele se encontra implicado no filme, que solicita o investimento do seu desejo, a projeção do seu corpo (semi-imobilizado) no corpo filmado, em movimento, pulsante. 0 filme trabalha para conquistar o espectador, para retirálo da indiferença; mas, longe de toda facilitação, só pode contrariá-lo. Trabalho a contrapelo, portanto, em uma dupla direção: ao espectador 0 filme não oferece nem as evidências do sensível - feito de mediações e de subtrações, ele recusa a transparência da representação - nem 0 mero reconhecimento das aparências oferecido pelos sentidos: se estes ganham uma potência é justamente a partir da sua necessária limitação.

Quanto ao procedimento metodológico adotado, nosso gesto é bem distinto do especialista que se dedica à análise fílmica. Enquanto este dispõe de um aparato formal que lhe permite decompor o filme em sua estrutura e apanhar a articulação interna dos seus recursos expressivos, procuramos nos colocar ao lado do espectador (por assim dizer), tentando compreender os efeitos que o filme produz no tempo mesmo da sessão, isto é, à medida que se desenrola. Longe de todo subjetivismo, foi preciso assumir nosso próprio lugar de espectadores e afastar a figura de um espectador ideal, decalcado da posição e das atitudes do analista, que se orienta, sobretudo, pelo que descobre com seus 
recursos críticos. 0 espectador, por sua vez, move-se entre saber e não-saber, excluído da cena e atraído por ela; oscilando sem cessar crer e duvidar - sem abandonar um em favor do outro; dividido entre o desejo de ver tudo e o seu impedimento (primeira violência sofrida, imposta pelas bordas do quadro e renúncia admitida: não posso ver tudo). Essa limitação reconhecida - mas que não extingue a vontade de ver - vem logo acompanhada de outro desejo: o de não querer ver tudo, coisa que já não depende daquilo que o enquadramento simultaneamente recorta e esconde: "Mantenho, diante do que o quadro me apresenta, uma recusa, uma reserva que perfura de negro a cena visível" (COMOLLI, 2008, p. 141). Essa cegueira, nem o mais treinado dos analistas poderia iluminar. É com ela que o espectador elabora - na incerteza e no desconforto - 0 que vê - o que deseja ver, o que não vê de todo, o que se recusa a ver, o que volta a querer ver. Ele não evolui da condição de não-saber para 0 saber, não vai da inconsciência à consciência, não abandona o que deseja ver por saber que não vê tudo. Enquanto o filme prossegue e mais o espectador se engaja no filme, mais os perigos o envolvem: violência do fora-decampo, movimento recorrente do olhar cegado e cegante, projeção utópica do corpo semiimobilizado sobre o corpo vivo dos atores. Esse mau lugar do espectador não poderia deixar de se estender aos que desejam escrever sobre a experiência que este filme (A falta que me faz) lhes impõe.

\section{Uma individuação pelos afetos e relações}

Diante de uma matéria sensível ao mesmo tempo deslumbrante e recheada de tensões em seu interior, o trabalho do espectador em A falta que me faz não se realiza sem uma parte significativa de incerteza, de dificuldade, de sombra. A começar pela identificação das personagens: ainda que os créditos iniciais nomeiem cada uma delas, a identidade de Alessandra, Valdênia, Priscila, Toca e Paloma permanecerá imprecisa durante boa parte do filme. A cor morena da pele, 0 compartilhamento da juventude e a presença muitas vezes conjunta em cena das meninas demandam uma atenção redobrada a cada detalhe do rosto e a cada variação da voz: a individuação das moças exige do espectador um esforço considerável, e quase não há garantias de que a tarefa se concretize.

Mas ainda que, por vezes, a identificação de cada uma delas se mostre fundamental para a narrativa, essa relativa confusão acaba por resultar num poderoso movimento de circulação das identidades, alimentado pela teia de relações que se estabelece entre as meninas. Em muitos momentos, só sabemos de uma através da fala das outras: a construção da subjetividade não é propriedade de cada uma, mas passa a compor um intrincado jogo de contaminações que resulta numa sorte de confecção coletiva das identidades, composta por ritmos, texturas e afetos diversos. Ao espectador, resta o trabalho de se colocar 
também em movimento, percorrendo atentamente essa linha de fronteira entre 0 ser e 0 ser alheio, que se tornou permeável: não para precisar limites e compreender 0 que as define enquanto seres individuais, mas para fazer reverberar, junto com o filme, as velocidades e os silêncios que povoam a constituição do grupo. A ausência de um traço próprio (marca de individualidade) é sublinhada no título do filme: a "falta" pode se referir tanto ao ser amado, quanto à indefinição em relação ao futuro. Como escreve Cláudia Mesquita em relação às personagens de $A$ falta que me faz (e de Morro do Céu, filme também analisado pela autora), elas são constituídas mais "[...] pela falta (do que desejam) e pela indefinição (de um porvir) do que por uma identidade (social, local, regional, comunitária) precisa e emoldurante (mesmo que traços 'identitários' atravessem muitas cenas)” (MESQUITA, 2010, p. 153).

Igualmente dificultosa é a compreensão do que se diz no filme. 0 sotaque e as expressões características daquela região do interior de Minas Gerais - que são partilhados por todas as meninas e que escutamos durante todo o filme - se materializam em um fraseado bastante particular, cuja apreensão exige um empenho do corpo e dos sentidos: a cada plano, é preciso abrir bem os ouvidos, acostumar-se ao ritmo próprio das frases e à forma peculiar com que terminam as palavras. A operação cinematográfica faz precisamente isto:
"[...] despertar, mobilizar, tornar mais intensos 0 olhar e a escuta em jogo no mundo" (COMOLLI, 2008, p. 209).

No entanto, ser espectador é também aprender junto com o filme, as "[...] ínfimas, pacientes e obstinadas forças do olhar e da escuta, experimentadas continuamente em seus limites" (COMOLLI, 2008, p. 187). À medida que imergimos no mundo de Curralinho, é todo um rico universo sonoro que se descortina a cada conversa, a cada verso de canção popular ou de poesia romântica. Aos poucos, a musicalidade das falas se adensa e faz emergir um mundo sensível recheado de pequenos detalhes e de uma arrebatadora força expressiva. A dificuldade inicial do espectador é transformada em potencial dramático, e se torna uma fonte singular de experiência estética.

A forma como a escritura do filme equilibra os seus diferentes componentes sonoros convoca o espectador a experimentar de outra maneira aquelas paisagens nas quais as meninas estão inseridas. ${ }^{1}$ É o que ocorre quando as vozes são justapostas aos ruídos do ambiente - destacando o som das águas nas sequências no rio, os ruídos do vento e dos pássaros. Em alguns momentos, 0 filme se vale de tempos mortos, imagens em que aparentemente nada acontece - como nos planos das inscrições e declarações de amor nas árvores ou naqueles em que vemos a casa do lado de fora,

Cabe lembrar, ainda, que quem assina o desenho de som do filme é o coletivo 0 Grivo que, além de ter formação musical, tem notória atuação com edição de som, mixagem e composição de trilhas sonoras originais para filmes. 0 Grivo atuou em inúmeros filmes da produtora Teia, de Belo Horizonte - da qual Marília Rocha fez parte -, e de outros realizadores, como Cao Guimarães. 
a rua deserta -, quando não vemos movimentos bruscos, apenas uma suave agitação das folhas - e é o som que inscreve essas imagens em um tempo real, do cotidiano. Na sequência final - que retomaremos adiante -, na estrada, podemos ouvir 0 vento que agita os cabelos da moça - ao passo que o ruído dos carros e da moto são atenuados e somos convidados a experimentar a sensação que ela experimenta. 0 som, ao mesmo tempo em que insere as situações e sujeitos filmados em um tempo e um espaço do cotidiano, convocam o espectador a uma experiência sinestésica de imersão em uma complexa paisagem sonora.

À medida que nossa imersão se intensifica, detalhes aparentemente banais da experiência retratada vão se tornando mais e mais significativos. Numa longa sequência, 0 enquadramento apanha as cinco moças em conjunto, formando uma pequena e animada roda de conversa. Em meio ao frio da Serra do Espinhaço, elas provam anéis, debruçamse carinhosamente umas sobre as outras, divertem-se com uma história recente. Sem abandonar 0 registro da brincadeira, Priscila refere-se ao esmalte nas unhas de Alessandra, dizendo, de forma provocativa, que "quem usa esmalte vermelho é rapariga". Entre o riso e a leve irritação, Alessandra se defende, dizendo que até sua filha Ingrid usa essa cor. E acrescenta que a própria Priscila, de vez em quando, também usa certo tom de vermelho. Agora é Priscila quem se defende: "aquilo lá não é vermelho, é Dara".
Já imersos na atmosfera íntima das relações entre as meninas, nossa atenção se dirige aos múltiplos afetos que habitam cada rosto e às variações possíveis de cada palavra. É só então que percebemos que, entre 0 esmalte vermelho e 0 Dara, há muito mais do que uma divertida querela sobre as colorações: entre uma tonalidade e outra, precipita-se na cena todo um espectro de diferenças sociais e de implicações políticas. $\mathrm{Na}$ delicada proximidade dos planos bem junto aos corpos, nosso acesso ao universo subjetivo das meninas é acompanhado por um mergulho nas tensões da vida cotidiana em Curralinho. De forma nem sempre evidente, mas inteiramente disponível aos olhos e ouvidos mais atentos, uma pluralidade de elementos relacionados à vida pública se sedimentam nos detalhes mais íntimos.

Nesse mundo de mulheres, é inevitável que os homens sejam sempre relegados à situação de coadjuvantes. Em alguns momentos, apenas ouvimos vozes masculinas invisíveis a preencher o campo sonoro; noutros, sua presença é restrita à borda ou ao fundo do quadro. Recorrendo ao refrão de um tema de novela, uma das personagens define com precisão a posição masculina no filme: "vocês não valem nada, mas eu gosto de vocês", brinca Priscila, dirigindose a dois rapazes que conversam na cozinha. Os homens não serão nunca 0 tema central, 0 corpo masculino nunca será valorizado pelo enquadramento, mas sua presença no fora-decampo contamina decisivamente as conversas e as relações. 
No entanto, ainda que o masculino se faça presente na mise-en-scène, é através do olhar feminino - ou antes, de um olhar feminino bastante particular - que teremos acesso ao universo filmado: uma perspectiva que se manifesta não apenas nos temas eleitos, mas no próprio modo de aparição dos corpos. Ao espectador, homem ou mulher, a demanda é por uma posição capaz de aderir à perspectiva marcadamente feminina da narrativa: para que 0 filme aconteça, é preciso despir-se das amarras do gênero e imergir em um mundo impregnado por uma experiência feminina singular, recriada pela câmera de Marília Rocha. Uma experiência marcada pela vivência da amizade e pela materialização do afeto - nas paredes, nas árvores ou no próprio corpo -, mas também pelo trabalho duro - na colheita das sempre-vivas ou no corte da lenha -, pelas complexas tensões familiares e pela resistência às pressões da sociabilidade em Curralinho (como manter um vínculo amoroso sem as restrições do casamento e sem os estigmas que pesam sobre as mulheres "amigadas" ou mães solteiras?). Para que haja relação - ou para que haja filme -, algum devir-outro se faz necessário. E é nessa difícil - e, ao mesmo tempo, imprescindível - alteração vivida pelo espectador que reside grande parte da potência estética e política inaugurada pelo filme.

Essa imersão do espectador no universo das moças, contudo, é construída aos poucos, plano a plano. Em grande parte do filme, predomina uma postura de observação cuidadosa do espaço e das personagens: fazendo jus à tradição do direto - quase esquecida pelo documentário brasileiro durante algum tempo (BERNARDET, 2003) -, a câmera se coloca bem próxima aos corpos, mas raramente interpela os sujeitos filmados, atendo-se mais aos elementos que surgem nas relações cotidianas entre as meninas. Parceiros dessa relativa transparência, somos instalados numa posição que é semelhante à da câmera: observamos com atenção, esperamos, adentramos pacientemente aquele mundo.

Pouco a pouco, o filme penetra os meandros afetivos de uma existência em comum, com um perceptível afeto equivalente do lado da realização. A partir de certo momento, A falta que me faz passa a investir mais na intervenção direta: as perguntas começam a surgir, e variam da conversa miúda do dia a dia - pequenos conflitos amorosos, brigas recentes, histórias familiares - às questões existenciais ("você acha que alguém se mata por amor?"). Após uma longa sequência em que vemos as meninas às voltas com os trabalhos domésticos -o feixe de lenha carregado nas costas, a louça mergulhada nas águas da bica, a roupa lavada e estendida ao sol -, vemos uma outra cena na qual duas delas estão reunidas em um pequeno quarto. Paloma lê poemas de amor escritos por Alessandra e Silvana, afixados na porta de um velho armário de madeira. Há um corte. Agora Alessandra é apanhada de perfil, sentada de costas para a janela; Paloma estendida confortavelmente sobre a cama logo atrás, apoiando a cabeça sobre os braços. Um 
menino - provavelmente irmão de Alessandra, que aparece brevemente em outras cenas do filme - parece ocupar um espaço entre a equipe e Alessandra, mas a câmera não se preocupa em enquadrá-lo (só ouvimos a sua voz). 0s corpos assim dispostos conferem ao quadro uma composição bastante incomum que, ao mesmo tempo, esconde e revela. Somos convidados a compartilhar da intimidade que a equipe de filmagem conquista junto às moças filmadas: adentramos aquela casa, aquele lar.

Alessandra ocupa o centro do quadro e é a ela a quem a equipe se dirige - embora todos eles estejam em constante diálogo, se inscrevendo na cena. Marília pergunta sobre seu pai, ela explica que ele morreu por causa de picada de barbeiro - compreendemos que se trata do causador da doença de Chagas, tão comum nas zonas rurais. Ouvimos bem ao fundo a voz da pequena Ingrid, latidos de cachorro e outros ruídos vindos da rua. 0 grupo conversa, entre si, relembrando o dia da perda do pai. Paloma fala detalhadamente sobre a reação dos familiares. "De que adianta a gente chorar, né, Marília? O que já passou, passou", afirma Alessandra. Há um outro corte. Mudando um pouco de assunto, Marília indaga às meninas se elas têm vontade de casar. Elas respondem prontamente que não, preferem a "farra" (contrariando as confissões inscritas no poema). Marília insiste "Mas você quer ficar morando com sua mãe o resto da vida?". E acrescenta: "É bom, menina, casar!". "Tem muita gente que está casando e está é sofrendo", responde Alessandra. No universo urbano da diretora, o casamento parece ser uma promessa de independência - a possibilidade dos filhos se verem separados da casa dos pais; no mundo de Alessandra, ao contrário, o casamento viria restringir sua liberdade. Em outros momentos do filme vemos que, para as meninas, romper 0 elo com a família não aparece como uma necessidade.

A conversa prossegue e logo teremos pistas de que seu pai enfrentava problemas com alcoolismo, envolvendo-se em brigas de tirar o sono de toda a família. Elas contam que ele chegara mesmo a ameaçar à mãe de morte. Apesar da complexidade do tema que anima a conversa, o grupo ri. Todo um repertório de relações familiares e de amizade é acionado pelas memórias que as personagens compartilham. Nesse movimento, o filme permite - uma vez mais - a nós espectadores fazermos experiência com a experiência delas. ${ }^{2}$

\section{Nem intrusos, nem confidentes}

A cada sequência, a interação entre a equipe e as personagens se intensifica, e a posição do espectador se torna mais complexa. Quando aqueles que filmam se vêem totalmente implicados na narrativa, num movimento radical de 
incorporação do antecampo, a mise-en-scène transborda para o lado de cá da câmera e envolve o espectador de uma maneira insuspeitada. 0 campo de observação se expande, a presença da equipe se torna sensível, e passamos a nos movimentar de maneira transversal entre quem filma e quem é filmado.

Mas essa interação não se dá de maneira simples, como se o filme pudesse inscrever de maneira soberana a experiência do outro. Em certo momento, 0 enquadramento nos mostra Valdênia no interior de seu quarto, enquanto ela (a gravidez já avançada) confere pacientemente 0 enxoval do bebê. A câmera se interessa pelos pequenos movimentos: a dobradura da roupa, a contagem das peças, a doce displicência da personagem - que faz e desfaz, repetidas vezes, a organização do enxoval em cima da cama. 0 registro conversacional é bem próximo da fala doméstica, e as perguntas de Marília e Clarissa ${ }^{3}$ se dirigem às escolhas da futura mãe: quais peças ainda faltam, quais são as que mais lhe agradam. A certa altura, respondendo à indagação de Marília, Valdênia diz que ainda não escolheu quem será a madrinha, e acrescenta: "Quem sabe ocê tá na lista?". E, dirigindo 0 olhar à equipe, completa: "Se ela quiser, né?". A realizadora não responde e Valdênia logo volta a contar as roupas. Nesse momento, A falta que me faz torna manifesta sua insuficiência, seu limite ético, seu reconhecimento de que nem tudo é filmável. Nesse recuo do filme, as opacidades presentes na relação entre quem filma e quem é filmado, tornam-se disponíveis para o julgamento do espectador: a mise-en-scène documentária é feita daquilo que vemos e ouvimos, mas também daquilo que resiste.

Nos minutos finais do filme, a equipe se encontra com Alessandra, em meio às pedras que compõem a paisagem. 0 plano se inicia com uma conversa sobre 0 trabalho, quando então Alessandra pergunta a Canarinho - responsável pelo som direto - sobre o que ele faz. Ele responde que faz "som para filme". Parece haver um pequeno desencontro na conversa, pois Alessandra demonstra não saber bem do que se trata. Ela pergunta o mesmo a outra pessoa da equipe que, detrás da câmera, responde "carrego isso para cima e para baixo". "Só isso?", ela pergunta, embora reconheça o trabalho que ele teve ao longo de todo o período de filmagem. E acrescenta: "Deve ser gostoso ficar andando...". A equipe, que está no fora-de-campo, é interpelada pela entrevistada. Nós, espectadores, que vemos e ouvimos a conversa, somos lembrados da mediação presente na escritura fílmica. Entre a entrevistada e nós, o filme faz ver que há todo um aparato cinematográfico que, embora não vejamos em quadro, se torna sensível na cena.

Marília diz estar curiosa com o fato de que Alessandra tem andado pensativa. Em dois planos anteriores víamos a personagem sozinha: 0 
primeiro, na cena em que as meninas dançam em um bar, Alessandra está sentada, aparentemente triste, digitando as teclas de um aparelho celular; na cena seguinte, vemos a moça no alto das pedras, igualmente solitária. Alessandra responde que, às vezes, vai para 0 alto da serra, assim como as amigas, para pensar na vida, quando quer paz ou quando está angustiada. "Por que você está tão tristinha?". Alessandra se esquiva em dizer.

Canarinho, então, pergunta sobre o moço - de Conceição, São Gonçalo ou Sete Lagoas, ele não sabe ao certo - que queria se casar com ela. Ela sabe que ele fala de Nacípio, um rapaz que realmente lhe pediu em casamento, mas que ela recusou. Marília também pergunta sobre o pai da Ingrid. Alessandra diz que ele já espera outro filho, de outra mulher - como dizem os boatos que circulam na cidade - e que eles não se casaram quando ela tinha seus 16, 18 anos porque ele, na verdade, só lhe propôs amigar - o que para ela não tem o mesmo valor do casamento.

Depois de um período de silêncio - a conversa é toda pontuada por pausas -, Marília pergunta sobre o pai do menino que ela está esperando. Ela diz que não sabe se ficarão juntos, pois o rapaz não sabe o que quer da vida. Mas ela admite: "Não adianta falar que ele não sabe o que quer da vida, que nem eu também, nem eu sei". Marília diz que vai voltar para ver o desenlace da história, mas Alessandra não acredita muito. "Vamos ver o que o destino reservou para nós". Ela sugere que 0 destino foi bom para Canarinho, porque ele se casou mais de uma vez. Depois que ele fala um pouco sobre a sua situação conjugal, ela brinca: "Você gosta de uma mulher, hein? Tu é bem safadinho!". E termina mais uma vez evocando 0 destino, num misto de incerteza e esperança num futuro diferente.

Nesse fragmento, é curiosa a maneira como se invertem os papéis entre quem pergunta e quem responde - de repente, quem fala sobre sua vida afetiva é uma pessoa da equipe - demonstrando que um elo de estabeleceu entre quem filma e quem é filmado - a ponto da entrevistada tomar liberdade para brincar e dirigir-lhes perguntas. A equipe não é confidente de Alessandra, mas também não é intrusa - no plano mencionado, podemos notar como ainda há certo constrangimento de Alessandra em falar sobre sua vida amorosa - ela se coloca diante da câmera de cabeça baixa, bastante acanhada. A relação que se estabelece oscila entre a proximidade e a distância.

Nós, espectadores, como aqueles que filmam, também não somos confidentes, tampouco intrusos. Não estamos nem "do lado de lá", como se pudéssemos nos identificar totalmente com aquelas que são filmadas - definitivamente, o mundo delas não é o nosso, muito embora possamos ver coisas comuns entre nós -, nem tampouco ao lado da equipe, que ocupa o lado de cá da câmera. A implicação da equipe na escritura do filme, explicitando a sua mediação e o seu vínculo com aquelas com quem interage, nos convida a assumir 
outro lugar. A relação que estabelecemos é triádica e 0 filme é o elemento mediador.

Das meninas que o filme acompanha, Alessandra é aquela que está grávida de seu segundo filho. É sobre ela que recaem os estigmas de ser mãe solteira - como bem conta Priscila, em outro momento, sobre o que pensam os moradores da região. Embora ela tenha dito para as amigas e para a equipe que não quer se casar - pois não estaria disposta a abrir mão de sua liberdade, de se vestir como quer ou de sair com as amigas -, nesse depoimento final ela demonstra que o plano de se casar não foi de todo descartado, muito embora caiba ao destino a sorte de encontrar ou não alguém. Um futuro feliz lhe parece incerto, bem como um reencontro com os realizadores: Alessandra duvida que Marília e sua equipe possam voltar um dia para ver o desenlace de sua história. Nesse momento, a conversa ganha um tom de despedida e, mais uma vez, o filme mostra seu limite.

\section{0 mundo que nos falta}

\section{A canção francesa (Je rêve de toi, de Arthur} H) - que surge como trilha para a sequência de imagens finais e dos créditos do filme - é um tema de amor. Se ela nos soa bem diferente das outras canções que pontuam o filme em vários momentos (a que abre o filme, as que animam as danças, aquelas que as meninas cantam umas para as outras ou que Valdênia escuta num pequeno rádio em seu quarto), isso se deve não apenas ao fato de ser cantada em outra língua, mas porque ela nos remete mais ao universo cultural dos realizadores do que da pacata Curralinho. Extraída de outro contexto, ela faz com que sentimentos evocados na sequência final ultrapassem a experiência específica daquelas meninas e expandam sua significação. Trata-se de uma dimensão que permeia todo o filme, mas da qual só tomamos consciência agora. Era preciso não saber para que entregássemos algo de nós, era necessária a ilusão para crer nessas imagens e sons que trazem algo de bem real e particular, mas que o filme - sem contradição -, ao combiná-los com elementos próprios dos mundos ficcionais, lhes outorga uma significação mais universal:

As pessoas que nós filmamos são todas por-
tadoras de uma reserva de ficção - singula-
ridade dos sujeitos e das vidas - que acaba
por se desenvolver ao longo da filmagem.
Não sendo atores profissionais, eles vivem a
filmagem como uma experiência real que os
transforma, que os perturba. Seduzidos, eles
ultrapassam a linha e se tornam persona-
gens (COMOLLI, 2011).

Ao final do filme, a canção francesa vem se juntar à monumentalidade atemporal das montanhas, às quadrinhas adolescentes, aos refrões sertanejos e às frases de Alessandra, que ainda reverberam em nós. Em meio à impressionante heterogeneidade dos elementos em cena, desprendemo-nos da realidade particular de Curralinho e, tomados pelos afetos encarnados nas imagens e na música, a juventude, a amizade e até mesmo a solidão surgem animadas pela promessa de aventura e liberdade. 
Nossa despedida do mundo de Alessandra, Valdênia, Priscila, Shirlene e Paloma é doce e triste, como uma canção ou um filme de amor. A sequência que encerra o filme é um travelling na estrada - bem ao modo dos road movies -, no qual vemos Shirlene abraçada a um rapaz, sobre a moto. 0 vento agita seus cabelos. Em outro ângulo, agora filmados de frente, vemos o rosto do rapaz que guia a moto e Shirlene na garupa. A paisagem, ao fundo, está desfocada, quase não distinguimos seus contornos - a essa altura, já bastante contaminada pelos afetos e relações que 0 filme apreende e proporciona, imantada ao mundo subjetivo do grupo de moças. A câmera desce e enquadra 0 braço da moça, que envolve o corpo do rapaz. Em sua mão, vemos 0 anel que comprara de Valdênia - que é enfeite, mas que bem poderia ser um anel de compromisso. Nesse momento começam os versos da canção: Je rêve de toi/ Même le jour/J'entends ta voix/ La voix de l'amour (Eu sonho com você, mesmo de dia, eu escuto tua voz, a voz do amor). Só agora descobrimos o quanto aquele "me" que consta do título do filme concerne também a nós, espectadores. Já perto do fim da sessão, nos damos conta de que o mundo que nos aparecia - na escuridão da sala - ao mesmo tempo como íntimo e exterior, agora nos falta.

\section{Referências}

A FALTA QUE ME FAZ. Personagens: Alessandra Ribeiro, Priscila Rodrigues, Shirlene Rodrigues, Valdênia Ribeiro, Paloma Campos. Direção: Marília Rocha. Diretora Assistente: Clarissa Campolina.
Produção: Luana Melgaço. Produtor Associado: Helvécio Marins Jr., Felipe Duarte. Fotografia: Alexandre Baxter, Ivo Lopes Araújo. Montagem: Francisco Moreira, Marília Rocha. Desenho de som: 0 Grivo. Trilha sonora: Arthur H. Design Gráfico: Marilá Dardot. Site: Fred Paulino. Coordenação de Distribuição: Felipe Duarte. Distribuição: Cia do Filme, Teia | Lume Filmes (DVD). Brasil: Teia/Lume Filmes, 2009. DVD (85 min), widescreen, cor.

ANDRADE, Fábio. Afetos medidos e desmedidos: A Falta Que Me Faz, de Marília Rocha (Brasil, 2009). Revista Cinética. 2010. Disponível em: < http://www. revistacinetica.com.br/faltaquemefaz.htm $>$. Acesso em: 23 jan. 2012.

BERNARDET, Jean-Claude. Cineastas e imagens do povo. São Paulo: Companhia das Letras, 2003.

COMOLLI, Jean-Louis. Ver e poder. A inocência perdida: cinema, televisão, ficção, documentário. Belo Horizonte: Ed. da UFMG, 2008.

\section{_ Cinéma contre spectacle. Lagrasse: Verdier, 2009 .}

. Suspens et désirs. 2011. Disponível em < http://cinemadocumentaire.wordpress. com/2011/01/20/suspens-et-desirs-par-jean-louiscomolli/> . Acesso em: 23 jan. 2012.

\section{GUIMARÃES, César. A experiência estética e a vida} ordinária. Revista eletrônica E-compós. v. 1, n. 1, p. 4, dez. 2004. Disponível em: < http://www.compos.org. br/e-compos > . Acesso em: 23 jan. 2012.

MESQUITA, Claudia. A presença de uma ausência: A falta que me faz e Morro do Céu. Revista Devires: Cinema e Humanidades. Belo Horizonte, v. 7, n. 2, jul./ dez. 2010. Disponível em: < http://www.fafich.ufmg. br/ devires/v7n2/>. Acesso em: 23 jan. 2012. 


\section{Mise-en-scène and aesthetic experience: the work of the spectator in Like water through stone (A falta que me faz)}

\section{Abstract}

By focusing on the filmic writing of Like water through stone (A falta que me faz), this paper seeks to describe the practical learning (of both the senses and meaning) that the movie session offers to the spectator. For this purpose, we try to identify the links between documentary mise-en-scène and the (psychic, sensorial, affective, imaginary) engagement that it demands from the spectator. We aim, on that account, at reaching a via media between filmic scene and the spectator's experience, so as to apprehend the ways in which it crosscuts (by means of identification as well as strangeness) the initial relation established between who films and the filmed subjects.

\section{Keywords}

Documentary. Aesthetic experience.

Mise-en-scène. Spectator.

\section{Mise-en-scène y experiencia estética: el trabajo del espectador en La falta que me hace (A falta que me faz)}

\section{Resumen}

$\mathrm{Al}$ detenerse en la escritura fílmica de La falta que me hace (A falta que me faz), el texto busca describir como ocurre el aprendizaje práctico (de los sentidos y del sentido) que la sesión de cine ofrece al espectador. Para eso, procuramos identificar la vinculación entre la mise-en-scène documental y el compromiso (psíquico, sensorial, afectivo, imaginario) que esta solicita del espectador. Intentamos alcanzar el camino del medio entre la escena del film y la experiencia del espectador, en el sentido de aprehender la manera con la cual ella viene - por medio de la identificación pero también del extrañamiento - a cortar transversalmente la relación inicial que se establece entre quienes filman y los sujetos filmados.

\section{Palabras-clave}

Documental. Experiencia estética.

Mise-en-scène. Espectador. 


\section{Expediente}

A revista E-Compós é a publicação científica em formato eletrônico da Associação Nacional dos Programas de Pós-Graduação em Comunicação (Compós). Lançada em 2004, tem como principal finalidade difundir a produção acadêmica de pesquisadores da área de Comunicação, inseridos em instituições do Brasil e do exterior.
E-COMPÓS I www.e-compos.org.br I E-ISSN 1808-2599

Revista da Associação Nacional dos Programas

de Pós-Graduação em Comunicação.

E-compós, Brasilia, v.16, n.1, jan./abr. 2013

A identificação das edições, a partir de 2008,

passa a ser volume anual com três números.

\section{CONSELHO EDITORIAL}

Afonso Albuquerque, Universidade Federal Fluminense, Brasil Alberto Carlos Augusto Klein, Universidade Estadual de Londrina, Brasil Álvaro Larangeira, Universidade Tuiuti do Paraná, Brasil André Luiz Martins Lemos, Universidade Federal da Bahia, Brasil Ângela Freire Prysthon, Universidade Federal de Pernambuco, Brasil Angela Cristina Salgueiro Marques, Faculdade Cásper Líbero (São Paulo), Brasil Antonio Roberto Chiachiri Filho, Faculdade Cásper Líbero, Brasil Arthur Autran Franco de Sá Neto, Universidade Federal de São Carlos, Brasil Benjamim Picado, Universidade Federal Fluminense, Brasil César Geraldo Guimarães, Universidade Federal de Minas Gerais, Brasil Cristiane Freitas Gutfreind, Pontifícia Universidade Católica do Rio Grande do Sul, Brasil

Denilson Lopes, Universidade Federal do Rio de Janeiro, Brasil Eduardo Peñuela Cañizal, Universidade Paulista, Brasil

Eduardo Vicente, Universidade de São Paulo, Brasil Eneus Trindade, Universidade de São Paulo, Brasil Erick Felinto de Oliveira, Universidade do Estado do Rio de Janeiro, Brasil Florence Dravet, Universidade Católica de Brasília, Brasil Gelson Santana, Universidade Anhembi/Morumbi, Brasil Gislene da Silva, Universidade Federal de Santa Catarina, Brasil Guillermo Orozco Gómez, Universidad de Guadalajara Gustavo Daudt Fischer, Universidade do Vale do Rio dos Sinos, Brasil Hector Ospina, Universidad de Manizales, Colômbia Herom Vargas, Universidade Municipal de São Caetano do Sul, Brasil Inês Vitorino, Universidade Federal do Ceará, Brasil Jay David Bolter, Georgia Institute of Technology Jeder Silveira Janotti Junior, Universidade Federal de Pernambuco, Brasil John DH Downing, University of Texas at Austin, Estados Unidos José Afonso da Silva Junior, Universidade Federal de Pernambuco, Brasil José Carlos Rodrigues, Pontifícia Universidade Católica do Rio de Janeiro, Brasil José Luiz Aidar Prado, Pontifícia Universidade Católica de São Paulo, Brasil Kelly Cristina de Souza Prudêncio, Universidade Federal do Paraná, Brasil.
Laan Mendes Barros, Universidade Metodista de São Paulo, Brasil Lance Strate, Fordham University, USA, Estados Unidos Lorraine Leu, University of Bristol, Grã-Bretanha Lucia Leão, Pontifícia Universidade Católica de São Paulo, Brasil Malena Segura Contrera, Universidade Paulista, Brasil

Márcio de Vasconcellos Serelle, Pontifícia Universidade Católica de Minas Gerais, Brasil

Maria Aparecida Baccega, Universidade de São Paulo e Escola Superior de Propaganda e Marketing, Brasil

Maria Ataide Malcher, Universidade Federal do Pará, Brasil

Maria das Graças Pinto Coelho, Universidade Federal do Rio Grande do Norte, Brasil Maria Immacolata Vassallo de Lopes, Universidade de São Paulo, Brasil Maria Luiza Martins de Mendonça, Universidade Federal de Goiás, Brasil Mauro de Souza Ventura, Universidade Estadual Paulista, Brasil Mauro Pereira Porto, Tulane University, Estados Unidos Mirna Feitoza Pereira, Universidade Federal do Amazonas, Brasil Nilda Aparecida Jacks, Universidade Federal do Rio Grande do Sul, Brasil Osvando J. de Morais, Universidade de Sorocaba, Brasil Potiguara Mendes Silveira Jr, Universidade Federal de Juiz de Fora, Brasil Renato Cordeiro Gomes, Pontifícia Universidade Católica do Rio de Janeiro, Brasil Robert K Logan, University of Toronto, Canadá

Ronaldo George Helal, Universidade do Estado do Rio de Janeiro, Brasil Rose Melo Rocha, Escola Superior de Propaganda e Marketing, Brasil Rossana Reguillo, Instituto de Estudos Superiores do Ocidente, Mexico Rousiley Celi Moreira Maia, Universidade Federal de Minas Gerais, Brasil Sebastião Guilherme Albano da Costa, Universidade Federal do Rio Grande do Norte, Brasil

Simone Maria Andrade Pereira de Sá, Universidade Federal Fluminense, Brasil Tiago Quiroga Fausto Neto, Universidade de Brasília, Brasil Suzete Venturelli, Universidade de Brasília, Brasil Valerio Fuenzalida Fernández, Puc-Chile, Chile

Veneza Mayora Ronsini, Universidade Federal de Santa Maria, Brasil Vera Regina Veiga França, Universidade Federal de Minas Gerais, Brasil

\section{COMISSÃO EDITORIAL}

Adriana Braga I Pontifícia Universidade Católica do Rio de Janeiro, Brasil

Felipe Costa Trotta I Universidade Federal Fluminense, Brasil

CONSULTORES AD HOC

Bruno Campanella, Universidade Federal Fluminense, Brasil

Christa Berger, Universidade do Vale do Rio dos Sinos, Brasil

Edison Gastaldo, Universidade Federal Rural do Rio de Janeiro, Brasil

José Luiz Braga, Universidade do Vale do Rio dos Sinos, Brasil

\section{EDIÇÃO DE TEXTO E RESUMOS I Susane Barros}

SECRETÁRIA EXECUTIVA I Juliana Depiné

EDITORACã̃ ELETRÔNICA I Roka Estúdio
COMPóS I www.compos.org.br

Associação Nacional dos Programas de Pós-Graduação em Comunicação

Presidente

Julio Pinto

Pontifícia Universidade Católica de Minas Gerais, Brasil juliopinto@pucminas.br

Vice-presidente

Itania Maria Mota Gomes

Universidade Federal da Bahia, Brasil

itania@ufba.br

Secretária-Geral

Inês Vitorino

Universidade Federal do Ceará, Brasil

inesvic@gmail.com 